\title{
Relevance of imaging in the evaluation of abdominal tuberculosis
}

\author{
A importância da imagem na avaliação da tuberculose abdominal
}

Antonio Luis Eiras de Araujo ${ }^{1}$

Tuberculosis is an infection highly prevalent worldwide, considered to be a global health problem by the World Health Organization. Currently, it is considered the most important communicable disease in the world whose dissemination reaches across the boundaries of developing countries. The number of tuberculosis cases has also been increasing in developed countries, mainly because of immigration between nations, as a consequence of acquired immunodeficiency syndrome (AIDS), and also because of the utilization of immunosuppressive drugs. To give an idea about the dissemination of such an infection, it is believed that one-half of the world's population has already had contact with the tubercle bacillus, and more than 10 million cases are diagnosed every year ${ }^{(\mathbf{1}, \mathbf{2})}$. Therefore, it is a subject of great importance for public health, and scientific studies on tuberculosis frequently contribute to a better understanding of such an entity, as well as to the definition of approaches to be adopted for its management and treatment.

Abdominal involvement in tuberculosis is the most common extrapulmonary form of this infection ${ }^{(3)}$. The presentation of $a b$ dominal infection is extensive, with involvement of multiple organs and systems ${ }^{(4)}$. The concomitant involvement of different segments is also usual, particularly in immunosuppressed patients ${ }^{(2)}$.

The clinical presentation of tuberculosis is variable and nonspecific, with non-pathognomonic signs and symptoms. Not rarely, it may mimic other infectious or inflammatory pathological diseases, or even neoplastic conditions. The same is true for imaging findings in different systems and organs affected by this mycobacteriosis ${ }^{(5-8)}$. It is a fact, however, that when one combines clinical findings with presence of some immunological deficiency, the patient's demographic origin and a relatively typical imaging presentation, the diagnosis of tuberculosis is fully tangible ${ }^{(4)}$.

All such described features make imaging findings of abdominal tuberculosis an important diagnostic tool. It should be highlighted that the correct characterization of the disease at an early stage is extremely important to reduce the morbidity of this infection. A late diagnosis and, consequently, appropriate but delayed treatment are intimately related to the increase not only of morbidity but also of mortality caused by tuberculosis. It is estimated

1. MD, Radiologist at Hospital Universitário Clementino Fraga Filho, Grupo Fleury and Rede D’Or, Rio de Janeiro, RJ, Brazil. E-mail: antonioeiras@gmail.com. that tuberculosis is responsible for 1.7 million deaths in the world, every year ${ }^{(1)}$.

The article published by Rocha et al. ${ }^{(9)}$ in the present issue of Radiologia Brasileira shows not only the importance of abdominal tuberculosis in the world health context, but also didactically describes the imaging findings in the different presentations of this abdominal infection. The abdominal cavity and the different disease presentations are comprehensively discussed. Omentum, gastrointestinal tract, solid abdominal viscera, genitourinary tract, and the musculoskeletal system are separately evaluated in relation to the involvement by tuberculosis. The main findings are described and exemplified. The imaging findings that lead to the diagnosis of tuberculosis are prominently described. When present, clinical correlation with imaging findings is described and valued. Eventual differential diagnoses are mentioned.

Finally, imaging methods, particularly the cross-sectional modalities such as computed tomography and magnetic resonance imaging allow for the demonstration of findings in abdominal tuberculosis. Imaging methods represent an important foundation in the follow-up of patients undergoing treatment, assisting in the definition of the approach to be adopted. Therefore, the study developed by Rocha et al. allows for confirmation of the importance of the imaging methods in the diagnosis and follow-up of patients undergoing treatment for abdominal tuberculosis.

\section{REFERENCES}

1. Lawn SD, Zumla Al. Tuberculosis. Lancet. 2011;378:57-72.

2. Aston NO. Abdominal tuberculosis. World J Surg. 1997;21:492-9.

3. Xu XF, Yu RS, Qiu LL, et al. Gallbladder tuberculosis: CT findings with histopathologic correlation. Korean J Radiol. 2011;12:196-202.

4. Gulati MS, Sarma D, Paul SB. CT appearances in abdominal tuberculosis. A pictorial essay. Clin Imaging. 1999;23:51-9.

5. Sinan T, Sheikh M, Ramadan S, et al. CT features in abdominal tuberculosis: 20 years experience. BMC Med Imaging. 2002;2:3.

6. Souza CG, Gasparetto EL, Marchiori E, et al. Espondilodiscites piogênica e tuberculosa: aspectos na ressonância magnética para o diagnóstico diferencial. Radiol Bras. 2013;46:173-7.

7. Zanetti G, Nobre LF, Mançano AD, et al. Sinal do halo invertido com paredes nodulares causado por tuberculose pulmonar, confirmada por cultura do escarro [Qual o seu diagnóstico?]. Radiol Bras. 2013;46(6):ix-x.

8. Ceratti S, Pereira TR, Velludo SF, et al. Tuberculose pulmonar em paciente com artrite reumatoide durante tratamento imunossupressor: relato de caso. Radiol Bras. 2014;47:60-2.

9. Rocha EL, Pedrassa BC, Bormann RL, et al. Tuberculose abdominal: uma revisão radiológica com ênfase em achados de tomografia computadorizada e ressonância magnética. Radiol Bras. 2015;48:181-91. 